\title{
Clostridium difficile isolated from the stool of a patient with pseudomembranous colitis following ampicillin plus flucloxacillin (Magnapen) therapy
}

\author{
ROGER J. MORGAN \\ M.B., D.A., M.R.C.P. (U.K.) \\ F. D. LEE \\ M.D., F.R.C.Path
}

\author{
C. G. Gemmell \\ B.Sc., Ph.D., M.I.Biol.
}

W. LANG

M.B., Dip. Obs., R.C.O.G., F.R.C.S.

\author{
R. I. RUSSELL \\ M.D., Ph.D., F.R.C.P. \\ Gastroenterology Unit, ENT Unit, and Departments of Pathology and Bacteriology \\ Royal Infirmary, Glasgow
}

\begin{abstract}
Summary
A case is reported of the isolation of Clostridium difficile from the stool of a patient with antibioticrelated pseudomembranous colitis.

\section{Introduction}

The diagnosis of pseudomembranous colitis is histological. Recent bacteriological studies of faeces and faecal isolates from these patients suggest that a clostridial toxin may be implicated in the pathogenesis of antibiotic-induced pseudomembranous colitis (Rifkin et al., 1977). Clostridium difficile may be the responsible organism (George et al., 1978; Larson et al., 1978).
\end{abstract}

\section{Case report}

A 45-year-old woman underwent pharyngolaryngectomy for a post-cricoid carcinoma. Postoperatively she was given a 12-day course of ampicillin $250 \mathrm{mg}$ plus flucloxacillin $250 \mathrm{mg}$ (Magnapen). On the sixteenth postoperative day she developed fever and watery diarrhoea with the passage of 12 motions daily. She had a second operation 30 days after the first. Postoperatively she received a second course of Magnapen. Her diarrhoea continued and after 7 days the Magnapen was stopped. Gentamicin was started 2 days after, and metronidazole 13 days after the second operation for an infected fistula. At that time sigmoidoscopy showed a white oedematous mucosa covered in small polypoid lesions and histological examination of a rectal biopsy confirmed the presence of pseudomembranous colitis. Stool culture grew

Correspondence: Dr R.I. Russell, Gastroenterology Unit, Glasgow Royal Infirmary, Glasgow G4 OSF.
C. difficile and a toxin was found in an extract of the patient's stool.

During the illness the patient was neither shocked nor dehydrated (she had been maintained on nasogastric feeding following the first operation), although she did become hypoalbuminaemic.

The pseudomembranous colitis healed without any specific treatment, although it is not certain whether the gentamicin or metronidazole had any effect on the disease.

\section{Discussion}

An organism resembling $C$. difficile (Hafiz and Oakley, 1976) was isolated from the patient's stool by anaerobic culture on blood agar containing gentamicin. The characteristics of this organism include the fermentation of glucose and hydrolysis of salicin, lack of activity with lactose and sucrose, and neither lecithinase nor urease activity. On the basis of these last 2 criteria, distinction can be made from C. sordellii (Sterne and Batty, 1975), an agent which was previously thought to be the organism responsible for pseudomembranous colitis (Rifkin et al., 1977).

The role of $C$. difficile as the aetiological agent in pseudomembranous colitis has been emphasized by the finding of cytotoxic activity towards embryonic lung fibroblasts in tissue culture in an extract of the patient's stool. It has also shown that this toxin is absent in ulcerative colitis, salmonellosis and healthy adults: and that it is absent after the pseudomembranous colitis has remitted (Larson et al., 1977, 1978). Such a toxin was present in a laboratory culture of a faecal isolate from the present patient.

These findings agree with recent studies from 
Larson et al. (1978) and George et al. (1978) who have found $C$. difficile in 5 patients with pseudomembranous colitis.

This case supports present views on the aetiology of pseudomembranous colitis and emphasizes the importance of sigmoidoscopy, biopsy and bacteriology in the investigation of a patient with antibioticrelated diarrhoea.

\section{References}

George, L.W., Sutrer, V.L., Foldstein, E.J.C., Ludwig, S.L. \& Finegold, S.M. (1978) Aetiology of antimicrobialagent-associated colitis. Lancet, i, 803.
Hafiz, S. \& OAKLeY, C.L. (1976) Clostridium difficile: $\$ isolation and characteristics. Journal of Medical Micro- $\stackrel{\varnothing}{\circledR}$ biology, 9, 129.

Larson, H.E., Parry, J.V., Price, A.B., Davies, D.R., $\stackrel{\subsetneq}{\rightrightarrows}$ Dolby, J. \& TYRrell, D.A.J. (1977) Undescribed toxin in pseudomembranous colitis. British Medical Journal, $1,1246$.

Larson, H.E., Price, A.B., Honour, P. \& Borriello, S.P. (1978) Clostridium difficile and the aetiology of pseudomembranous colitis. Lancet, i, 1063.

Rifkin, G.D., Silva Jr, J., Fekety Jr, F.R. \& SACK, R.B. (1977) Antibiotic induced colitis: Implication of a toxin neutralized by Clostridium sordelli antitoxin. Lancet, ii, 1103.

Sterne, M. \& Batty, I. (1975) Pathogenic Clostridia, 3rd edn, p. 107. Butterworths, London. 